\title{
Practice visits as a tool in quality improvement: acceptance and feasibility
}

\author{
P van den Hombergh, R Grol, H J M van den Hoogen, W J H M van den Bosch
}

\begin{abstract}
Objective-To evaluate the feasibility and acceptance of (a) two programmes of assessment of practice management in a practice visit: mutual practice visits and feedback by peers versus visits and feedback by non-physician observers and (2) the practice visit method used in these programmes (the visit instrument to assess practice management and organisation (VIP) - a validated Dutch tool).

Design-Prospective, randomised intervention study with the two programmes, follow up after one year. General practitioners (GPs) were visited after each programme and after the revisits by nonphysician observers a year later.
\end{abstract}

Setting-General practices in the Netherlands in 1993 and 1994.

Subjects-A total of 90 GPs in 68 practices. At follow up after 1 year there were 81 GPs in 62 practices.

Main measures-Scores (mainly five point scales) for questions on appreciation and acceptance; after the follow up visit a year later, scores for questions on feasibility and practicality of the improved procedure and feedback report.

Results-Data of 44 mutual visits by peers were compared with data of 46 visits by non-physician observers. A visit by a nonphysician observer was appreciated significantly more. After the practice visit at one year follow up, the participants reported to have appreciated the visit and the feedback report and to prefer feedback of a non-physician observer to that of a peer. Participants' reports on the procedure and the presentation of the feedback provided clues for the improvement of visit procedures.

Conclusions-A practice visit and feedback by a non-physician observer is more appreciated than a visit and feedback by a colleague. A practice visit with the VIP by a non-physician observer is a simple, easy, and well accepted method for assessing practice management.

(Quality in Health Care 1999;8:167-171)

Keywords: practice visit; outreach visit; feasibility; practice management; educational assessment; peer review; facilitator

In the previous article in this issue of Quality in Health Care (page 161) we showed that mutual practice visits by peers resulted in a more marked change of practice management than practice visits and feedback by non-physician observers. Although actual change is important for acceptance of a quality improvement method, good feasibility is just as crucial. This requires careful evaluation because practice visits require manpower, money, and time, and need to be accepted and appreciated by the profession. So far few studies on feasibility have helped policy makers in their decision to use practice visits extensively for quality improvement. Houghton calculated that five yearly practice visits of 33000 general practitioners (GPs) in the UK wishing to become fellows of the Royal College of General Practitioners would be virtually impossible and a waste of resources when it was concluded that $95 \%$ of the practices are not substandard. ${ }^{1}$ Large scale practice visit projects in Australia and Canada have not taken away uncertainty about the feasibility and acceptance of combined educational and summational practice visits, let alone their cost effectiveness. Is it worth the effort and visitors' time if, as in Australia, 55\% of the practices meet all standards required, rising to $75 \%$ after one or two standards (mostly vaccine storage and contaminated waste disposal) have been met. ${ }^{2}$ Although the visitor learns a lot about the practice, most GPs feel that the scheme is unnecessarily complex and daunting. ${ }^{3}$ In Canada there is a comparable approach intended to track down and improve substandard practices and GPs. However, acceptance of the visit and of the improvement scheme by the identified substandard practices has been below expectation. ${ }^{4}$ All these practice visit methods use summational assessment and intend also to be educational to achieve quality improvement. ${ }^{5}$

In the 1970s, purely educational practice visits by peers were received with considerable enthusiasm in the Netherlands. ${ }^{6}$ Participation was strictly voluntary, but the enthusiasm did not last and the method was not evaluated. Tasmania runs a similar interpractice visit programme, but shows declining numbers of volunteering GPs. ${ }^{8}$ In Sweden, a promising educational practice visit method is part of the "quality tool box" introduced in 1992, but it is still being further developed. ${ }^{9}$

Previous publications on the various methods used in different countries ${ }^{10-13}$ yield insufficient information on feasibility and acceptance. A question is, for instance, whether the common approach of mutual practice visits by peers is appreciated or accepted more than practice visits by non-physician observers. Equally important is the procedure: how should GPs be recruited; which type of observer is preferred for giving feedback; how should the feedback be presented; are the 
activities and number of questionnaires well proportioned as well as the time they require; does the GP recognise his care or practice management in the feedback; is the practice visit worth the time as well as the costs; does it lead to change according to the GP or practice; and does one want a repeat visit? ${ }^{14-16}$

Based on publications and on experiences with the different practice visit methods, we developed the practice visit instrument to assess practice management and organisation (VIP); an educational method with only one assessor. ${ }^{17}$ Our previous article dealt with the effectiveness of this practice visit method (page 161); here we report on its feasibility. We compared two programmes in particular: mutual visits by peers and visits by a non-physician observer.

\section{Methods}

STUDY DESIGN AND PARTICIPANTS

We invited 15 local GP groups - teams of GPs sharing responsibilities for care and continuity and taking care of continuing medical education and audit - with a total of 109 GPs to participate in the study. Recruitment implied advertising in medical journals or during postgraduate courses and approaching key people in the profession as well as representatives of GP groups. On application, the GP groups were randomly assigned to either programme - mutual visit by peers or a visit by a non-physician observer (experienced practice assistants/nurses trained as facilitators). ${ }^{17}$ In each programme the validated practice visit method VIP was used. ${ }^{18}$ After a year each GP was visited again by a non-physician observer.

INSTRUMENTS AND VARIABLES

The practice visit method $\left(\mathrm{VIP}^{1718}\right)$ consists of instruments for data collection, a procedure for the visit, and a prestructured feedback report (box 1). Feedback in the report implied comparison of individual $\mathrm{GP} /$ practice scores with scores of 59 GPs in the pilot study with the VIP and a year later with scores of 110 GPs (norm referenced scores). The GP discussed the feedback report either with a peer or with a non-physician observer in a one hour meeting. In both programmes the GPs had a two hour meeting with their local GP group after all visits had been completed (box 1). GPs did not receive training except for the brief introduction and a written instruction. The nonphysician observers had three days of instruction. They were encouraged to present the feedback report as a mirror to the GP and to ask him to comment on his results. The observer refrained from comment unless she was asked to do so.

EVALUATION OF FEASIBILITY AND ACCEPTANCE OF THE TWO PROGRAMMES

To evaluate the feasibility of both programmes (table 1) the GP was invited to answer questions in a written questionnaire after each practice visit. There were questions on

- Appreciation (for example, to what extent did the GP like the method, find the
30-60 minutes before the visit:

- Introduction; setting of date and time of the visit

- The participants receive the manual with the questionnaires

- The practice assistant hands out 30 patient questionnaires to patients waiting for consultation

- Questionnaires for the GP and practice assistant and 30 patient questionnaires are completed and sent to the observer

- Observer (or secretary) makes the provisional feedback report with the first data

On the day of the visit (four to five

hours for the observer, one to two

hours for the participant)

- Arrival of the observer on the arranged date

- The colleague or the non-physician observer completes the observation of the practice and the medical records

- The colleague or the non-physician observer completes the feedback report with the collected data

- The colleague or the non-physician observer asks the GP to comment on the visit and the feedback report

- The colleague or the non-physician observer discusses the conclusions with the GP (one hour)

- An action list is made for quality improvement in practice management

- Both observer and GP fill out an evaluation form

After completion of all observations in a group

- The GPs meet to evaluate the results of each participant in the group

Box 1 The two programmes of the practice visit, visits by peers and non-physician observers

feedback clear, pleasant, etc (seven questions, Cronbach's $\alpha=0.72)^{19}$ )

- Acceptance (for example, to what extent was the visit experienced as a burden, did it pose a threat to the practice assistant or GP, etc (four questions, Cronbach's $\alpha=0.67$ ))

- Reported change (for example, was the visit instructive, did it result in plans for change, etc (four questions, Cronbach's $\alpha=0.69$ ))

- For each of the six chapters of the feedback report questions on the GP's recognition of his practice management in the feedback (six questions Cronbach's $\alpha=0.53$ ).

To analyse the differences in feasibility between the two programmes we used the $\chi^{2}$ test for each item (five point scale). For the difference between the average scores of the dimensions we used a multilevel variance analysis to correct for the intracluster correlation within a practice (level $1=\mathrm{GP}$, level $2=$ practice).

EVALUATION OF THE PROCEDURE AND THE FEEDBACK REPORT OF AN IMPROVED METHOD After a year the GPs were visited again. The same instruments were used in the visit, but 41 
Table 1 Opinion of the GPs on appreciation, acceptance, change, and the quality of the feedback (percentages (fully) agree; $n=74$ ). Mutual visits by peers $v$ non-physician observers



Significance of the difference ${ }^{\star} \mathrm{p} \leqslant .05 ;{ }^{\star \star} \mathrm{p} \leqslant .01 ;{ }^{\star \star \star} \mathrm{p} \leqslant .001\left(\chi^{2}\right)$.

†The differences in average scores on the dimensions were tested using multilevel variance analysis (Proc mixed; SAS).

$\ddagger$ Explained variance by the practice.

non-discriminative or questionable indicators had been removed. All revisits were by non-physician observers. We adapted the procedure and the layout of the feedback report. We questioned all GPs extensivelymainly using five point Likert scales - on their satisfaction with this improved method, its procedure, layout of the feedback report, number of questionnaires, patient records, and aspects of the feedback.

\section{Results}

Of 15 GP groups, one group of nine GPs refused to be randomly assigned; 10 GPs withdrew for personal reasons (rebuilding, too busy, close to retirement). The remaining 14 groups consisted of 90 GPs in 68 practices: seven groups with $44 \mathrm{GPs}$ were assigned to mutual visits by peers and seven groups with 46 GPs to visits by non-physician observers. Both groups were comparable for sex, practice assistants, own treatment room for the practice assistant, working full time, having done vocational training, the number of GPs, being a member of the Dutch College of GPs, having a practice in an urban area, and being a GP trainer. However, significantly more single handed practices (28 $v 13)$ were visited by non-physician observers. After a year nine visits were not repeated for various reasons (GP had changed practice, was ill, had died, retired, had no time, was not interested anymore). The dropout was equally distributed over both programmes.

FEASIBILITY AND ACCEPTANCE

Fewer questionnaires on feasibility were returned by GPs after mutual visits by peers (32/ $44 ; 73 \%$ ) than after visits by non-physician observers $(42 / 46 ; 91 \%)$. A visit by a nonphysician observer was appreciated significantly more, but neither programme differed much in "acceptance" by the GP and in "reported change" (table 1). A full 100\% of the GPs visited by a non-physician observer rated the visit as "not unpleasant" against only $62 \%$ of the mutually visiting GPs. More GPs visited by a non-physician observer would recommend such a visit to all other GPs (78\% v 68\%) and these GPs also scored higher on recognition of their own practice management in the feedback than GPs visited by a peer.

The intracluster correlation explained by working in the same practice was low $(0 \%)$ for the acceptance of the practice visit by the GP and $25 \%$ for the reported change by the GPs.

Participants suggested a procedure of returning all questionnaires in advance, enabling the early processing of the answers in the feedback report and relieving the observer on the day of the visit. Other suggestions included adding useful information on each indicator to justify its presence in the method as well as histograms to plot one's score.

The practice visits with the improved VIP one year later were appreciated. The method was seen as clear and understandable and more effective than continuing medical education, resulting in change recommendable to all GPs, but not immediately resulting in corresponding training afterwards (table 2). For the procedures, the GPs reported that they preferred recruitment as a GP group rather than as individuals, preferred a non-physician observer to a colleague as an observer, and greatly appreciated the two hour discussion in the GP group afterwards. The feedback report was evaluated as transparent and understandable, balanced in its attention for the various aspects of practice management. The GPs valued the sumscores, histograms, and the additional information on the indicators as indispensable. They rated the number of 30 patient questionnaires as about right, 10 patient charts as probably not enough, and the number of 33 aspects as about right (table 3). They reported to have spent less time 
Table 2 Opinion of the participating GPs on the practice visit method with the improved VIP a year later ( $n=76$, percentages (fully) agree)

\begin{tabular}{|c|c|c|}
\hline Questions & $\begin{array}{l}\text { (Fully) } \\
\text { agree }(\%)\end{array}$ & $\begin{array}{l}\text { (Fully) } \\
\text { disagree }(\%)\end{array}$ \\
\hline \multicolumn{3}{|l|}{ Method itself } \\
\hline The method is clear and understandable & 95 & 0 \\
\hline Participation in this practice visit was pleasant & 75 & 3 \\
\hline The practice visit resulted in actual change & 58 & 21 \\
\hline $\begin{array}{l}\text { The practice visit results in more change than regular continuing } \\
\text { medical education }\end{array}$ & 68 & 8 \\
\hline $\begin{array}{l}\text { The practice visit stimulated me to participate in corresponding } \\
\text { continuing medical education }\end{array}$ & 26 & 32 \\
\hline I would recommend this assessment with the VIP to every GP & 86 & 4 \\
\hline \multicolumn{3}{|l|}{ Procedure } \\
\hline Individual GPs should be recruited instead of GP groups & 23 & 60 \\
\hline Method is too far reaching, reveals painful differences between GPs & 12 & 86 \\
\hline $\begin{array}{l}\text { I prefer a practice visit by non-physician observers to mutual visits } \\
\text { by peers }\end{array}$ & 64 & 12 \\
\hline $\begin{array}{l}\text { Non-physician observer helped to give the right attention to the } \\
\text { feedback }\end{array}$ & 74 & 8 \\
\hline $\begin{array}{l}\text { Discussing the feedback afterwards in the GP group is a valuable } \\
\text { activity }\end{array}$ & 70 & 6 \\
\hline \multicolumn{3}{|l|}{ Feedback report } \\
\hline Feedback is not transparent, too complex and detailed & 7 & 80 \\
\hline Some aspects get disproportionate amount of attention & 19 & 61 \\
\hline $\begin{array}{l}\text { Feedback in general gives an accurate picture of my practice } \\
\text { management }\end{array}$ & 87 & 3 \\
\hline $\begin{array}{l}\text { Reference scores (averages of all GPs) are indispensable for good } \\
\text { feedback }\end{array}$ & 91 & 0 \\
\hline $\begin{array}{l}\text { Sumscores and histograms of aspects provide useful additional } \\
\text { information }\end{array}$ & 77 & 1 \\
\hline $\begin{array}{l}\text { Text justifying the presence of indicators in the feedback was } \\
\text { instructive }\end{array}$ & 72 & 3 \\
\hline
\end{tabular}

than planned on each activity and indicated that one hour for the discussion with the observer after the visit was too short. Interestingly, they reported (in retrospect) to have spent only 75 minutes on the visit (less than the sum of the various activities) and found that time about right. The $90 \%$ who would like a repeat visit within five years was reassuring. The cost of mutual visits by peers was estimated to be about $£ 120$ for materials and overheads, plus eight hours of GP time. A visit by a non-physician observer (training, a day's visit, organisation, travel, materials, and overheads) would be about $£ 250$, plus four hours of GP time (table 4).

\section{Discussion}

As far as we know, the feasibility and acceptance of different practice visit programmes and procedures have not been studied previously so extensively. The results

Table 3 Opinion of the GPs on the quantity of data collected and on the time spent on each activity $(n=73)$

\begin{tabular}{|c|c|c|c|}
\hline Number of questionnaires and charts * & & Too many (\%) & Too few (\%) \\
\hline 30 patient questionnaires & & 14 & 11 \\
\hline 10 patient records & & 4 & 14 \\
\hline 33 aspects in the feedback & & 7 & 3 \\
\hline Time spent on various activities ${ }^{\star}$ & Reported time & Too long & Too short \\
\hline \multicolumn{4}{|l|}{ Time required for } \\
\hline The GP questionnaire & 45 minutes & 7 & 4 \\
\hline Preparing for the practice visit & 25 minutes & 5 & 3 \\
\hline Organising the patient questionnaire & 11 minutes & 3 & 10 \\
\hline The feedback discussion with the observer & 50 minutes & 0 & 11 \\
\hline Spending on the practice visit ${ }^{\star \star}$ & 75 minutes & 5 & 5 \\
\hline
\end{tabular}

* The answer category was too many (long); about right; too few (short).

$\star \star$ The reported total time is much less than the sum of the reported time on each activity.

Table 4 Estimate of the average costs and time required of the GP for one practice visit

\begin{tabular}{lll}
\hline Costs per visit & Materials and overhead costs & GP hours \\
\hline Mutual visits by peers & $£ 120$ & 8 \\
Visit by a non-physician observer & $£ 250$ (including $£ 130$ labour) & 4 \\
\hline
\end{tabular}

yield many clues on how a practice visit may be conducted with more success.

The method was well accepted and appreciated by most of the participants, although less by GPs who mutually visited each other's practice. Our study supports the view that data collection in a practice visit should preferably be done by trained external non-physician observers, ${ }^{20}$ who are also better appreciated than peers in the discussion of the feedback. GPs dislike data collection and tallying, yet the peer visit probably helped them to improve their own practice management in particular (previous article).

Gradually the outline of an acceptable and feasible practice visit method becomes clearer. In our view, enthusiastic initiatives for mutual practice visits - still common - are not the preferred approach, certainly not if undertaken without a valid and reliable method. Recruitment of a group of GPs may be better accepted than individual recruitment. It may seem obvious, but our results confirm that a simple and easy practice visit procedure with a minimal burden for the GP and the practice results in better appreciation. The GP should not be responsible for the format and organisation of the visit and should only be involved in data collection, if such is instructive. Well documented and useful information on each indicator not only helps the realisation of improvements but also prevents fruitless discussion and doubt. Reference scores and histograms provide further stimulus, and we got indications about the optimum number of patient questionnaires and patient records.

Our practice visit method focuses on actual information and feedback. It restricts judgments by the observer to a minimum by using instruments collecting factual information in a prestructured feedback report. ${ }^{17}$ The feedback report is therefore less dependent on the qualifications, mood, or incontrovertibility of the observer, and this may have boosted acceptance. Whoever observed, it would result in the same feedback report (inter-raterreliability).

To find many highly trained and knowledgeable GP observers and to ask them to conduct practice visits instead of their other work may be unrealistic. ${ }^{21}$ Also, the more qualified the observer, the more this observer will be experienced as an inspector and be less of a peer. ${ }^{16}$

The training of our non-physician observers was focused on serving as an assistant in helping GPs to interpret the feedback rather than giving comment. Just as in re-evaluation counselling, this was based on the assumption that people flourish when they are listened to well. ${ }^{22}$

The good test features, the low cost, and the easy programme may explain why $90 \%$ of the GPs reported to want a follow up within two to five years. Also, the method helps to improve the practice management of all GPs, including the ones with already high scores on most aspects, and this may have contributed to the satisfaction of the GPs with the method.

The conclusions have to be interpreted with some caution. Some scores may just reflect overall satisfaction and are only relevant relative to the scores on other questions. The 
questionnaire after the visit may reflect the relief of having withstood the visit. In the previous article we discussed some of the drawbacks of the study design. The design did not allow for ascribing the low appreciation of a colleague to his role in giving feedback. Other factors may well be more important for the low appreciation: the burden of data collection, organisational difficulties, or lack of training.

The low response of GP questionnaires after peer visits were probably due to GPs who were tired of the mutual visit and would have made the actual difference in appreciation even more distinct. That - after the follow up visit by a non-physician observer-only $12 \%$ of the GPs reported to prefer a visit by a peer further confirms the difference in appreciation. Maybe GPs were just being polite when they say they liked the mutual practice visit very much. They may not have liked the colleague or may have felt uncomfortable being commented on by a peer they had not chosen. However, the two hour discussion afterwards among peers in the GP group was highly appreciated, and the GP group may be a more comfortable forum for the discussion of the feedback than a conversation with one colleague.

For further improvements of the visit method we may have to look for ways of preserving the advantage of experiencing the culture and organisation of another practice. A likely improvement may be feedback at the level of analysis - practice or GP levelresulting in a practice report for the practice team and an individual report for each GP. To combine optimum change and optimum appreciation we propose to study a procedure in which a non-physician observer collects the data; prepares and gives feedback; invites a colleague from the GP group to come along and observe equipment, the doctor's bag, and medical records; and joins the discussion of the feedback report.

The role of the non-physician observer (non-GP) both in conducting practice visits and in helping to promote quality improvement deserves more attention.

1 Houghton G. General practitioner reaccreditation: use of performance indicators. Br f Gen Pract 1995;45:677-81.

2 Miller G, Stirton J, Smith D, et al. Field test of entry standards for general practice. Condensed report; RACGP: 1995.

3 Hull R. Audit of general practice in Australia. Medical Audit News 1995;5:92.

4 Borgiel A. Practice assessment: the patient perspective. Abstract No. 2007. Dublin: WONCA, 1998.

5 Salisbury C. The Australian quality assurance and continuing education program as a mode for reaccreditation of ing education program as a mode for reaccreditation of general practitioners in

6 Bergsma JJ. Onderlinge toetsing der praktijkvoering door huisartsen. [Mutual assessment of practice management by GPs.] Huisarts Wet 1966;9:82-7.

7 Commissie Toetsing van het NHG. Onderlinge Praktijkobservatie. Een draaiboek voor koppels huisartsen. [Mutual practice organisation. A script for GP couples.] Huisarts Wet 1984;27:130-4.

8 Gill G, Van den Hombergh P, Borgiel A, et al. Interpractice visits: experiences in 4 countries. Abstract No 380 . Dublin: WONCA, 1998

9 Eliasson G, Berg L, Carlsson P, et al. Facilitating quality mprovement in primary health care by practice visiting. Quality in Health Care 1998;7:48-54.

10 Royal College of General Practitioners. What sort of doctor? Assessing quality of care in general practice. London: RCGP, 1985

11 College of Family Physicians of Canada. Practice assessment program. Montreal: CFPC, 1990.

12 Royal Australian College of General Practitioners. Entry standards for general practices. Sydney: RACGP, 1996.

13 Royal New Zealand College of General Practitioners. Quality in family practice training program. Wellington: RNZCGP, 1988

14 Royal College of General Practitioners. Guide and criteria for fellowship by assessment. Occasional Paper 50. London: RCGP, 1990.

15 Marinker M. Medical audit and general practice. London: BMJ Books, 1990.

16 Scrivens E. Policy issues in accreditation. Editorial. Int $\mathcal{f}$ Qual Health Care 1998;10:1-5.

17 Van den Hombergh P, Grol R, Van den Hoogen HJM, et al. Assessment of management in general practice: validation of a practice visit method. Br F Gen Pract 1998;48:1743-50.

18 Van den Hombergh P, Grol R, Smits AJN, et al. Visitatie van huisartspraktijken; naar toetsing van de praktijkvoering. [A practice visit to assess the organisation of the general practitioner] Huisarts Wet 1995;38:169-74.

19 Cronbach LJ, Meehl PE. Construct validity in psychological tests. Psychological Bulletin 1955;52:281-302.

20 Difford G. Defining essential data for audit in general practice. BMF 1990;300:92-4.

21 Bohigas L, Brooks T, Donahue $\mathrm{T}$, et al. A comparative analysis of surveyors from six hospital accreditation programmes and a consideration of the related management issues. Int F Qual Health Care 1998;10:7-13.

22 Sackin P, Barnett M, Andrew E, et al. Peer supported learning. Editorial. Br f Gen Pract 1997;47:68-9. 